\title{
Effect of Sweet Orange and Pomegranate Peel Extract Combination on in Vivo Antidiabetic and Wound Healing Activity
}

\author{
Evi Sovia* \\ Laboratory of Pharmacology, Faculty of Medicine \\ Universitas Jenderal Achmad Yani \\ Cimahi, Indonesia \\ *evi.sovia@lecture.unjani.ac.id \\ R. J. Nurjatin \\ Laboratory of Physiology, Faculty of Medicine \\ Universitas Jenderal Achmad Yani \\ Cimahi, Indonesia
}

\author{
Rini Sundari Harjono \\ Laboratory of Clinical Pathology, Faculty of Medicine \\ Universitas Jenderal Achmad Yani \\ Cimahi, Indonesia
}

\begin{abstract}
Diabetes mellitus is a disease characterized by increased blood glucose levels (hyperglycemia). Diabetic wound healing is slower than healthy individuals. Both sweet orange (Citrus sinensis) and pomegranate (Punica granatum) peel have an antihyperglycemic effect. This study investigated the effect of the combination of both these plants on blood glucose level and wound healing in alloxan-induced diabetes rats experimentally. Rats were divided into four groups. One group as a normal group and three treatment groups that induced by intraperitoneal injection of a single dose alloxan $200 \mathrm{mg} / \mathrm{kg}$. One week after diabetes induction, full-thickness excision wounds were made in hyperglycemias rats and were divided into diabetes groups that given CMC 1\%, the group that given a combination of sweet orange $100 \mathrm{mg} / \mathrm{kg}$ and pomegranate $50 \mathrm{mg} / \mathrm{kg}$ peel ethanol extract and the group that given combination of sweet orange 200 $\mathrm{mg} / \mathrm{kg}$ and pomegranate $100 \mathrm{mg} / \mathrm{kg}$ peel ethanol extract. The treatment was given for 12 days. Blood glucose levels and the rate of wound closure were measured on the twelfth day. The combination of sweet orange and pomegranate peel extract showed a significant $(p \leq 0.05)$ reduction in blood glucose and time to wound closure compared with the normal and diabetes control. Based on these results, a combination of sweet orange and pomegranate have a potential effect as an antidiabetic agent and treatment of chronic wounds in diabetes.
\end{abstract}

Keywords—antidiabetes, wound healing, orange, pomegranate

\section{INTRODUCTION}

Diabetes affects hundreds of millions of people worldwide. Diabetic individuals exhibit impairment in the healing of acute wounds. Moreover, this population is prone to develop chronic non-healing diabetic foot ulcers (DFUs), which are estimated to occur in $15 \%$ of all persons with diabetes. DFUs are a serious complication of diabetes and precede $84 \%$ of diabetes- related lower leg amputations [1,2].

Sweet orange (Citrus sinensis) is well known for its medicinal and nutritional properties all over the world. Its plant parts like peel, flower, fruit, and juice are used as traditional medicine. The major medicinal properties of orange include anti-bacterial, anti-fungal, anti-diabetic, cardio protective, anticancer, anti-arthritic, anti-inflammatory, anti-oxidant, antitubercular, anti-asthmatic, and anti-hypertensive [3]. Sweet orange also possesses an anticoagulant component and may serve as cardioprotective and significantly decreased blood pressure [4,5]. A previous study showed that the ethanolic extract of sweet orange peel significantly attributed to healing potential in diabetic conditions [6].

The potential therapeutic properties of pomegranate (Punica granatum) are wide-ranging and include treatment and prevention for cancer, cardiovascular disease, diabetes, dental conditions, and erectile dysfunction, protection from ultraviolet (UV) radiation, and antimicrobial [7]. Peel powder extract of pomegranate contains a good source of natural compounds that have an important role as hypoglycemic and hypocholesterolemic agents [8]. Pomegranate peel extract also decreased significantly fasting blood glucose levels [9]. Pomegranate rind extract increased wound contraction of the excision wound in addition to the burn wound. Additionally, Pomegranate rind extract improved collagen synthesis and restricted the permeation of neutrophil dose autonomously [10].

Both orange and pomegranate have antidiabetic and wound healing activity, if combined, it is expected to increase its potential antidiabetic and wound healing. Therefore, this study 
aims to examine the potential combination of ethanol extract of sweet orange and pomegranate peel as antidiabetic and its role in wound healing. The results of this study are expected to be the basis for the development of a combination of orange peel extract and pomegranate peel as antidiabetic and wound healing.

\section{MATERIALS AND METHODS}

\section{A. Plant Material}

Citrus sinensis obtained from garden in Kediri, East Java and pomegranate obtained from garden in Sumedang, West Java. The plant was identified by the Department of Biology, School of Life Science, Bandung Institute of Technology with letter No. 4845/II.CO2.2/PL/2018.

\section{B. Preparation of Orange and Pomegranate Peel Ethanol Extract}

Orange and pomegranate fresh peel were air-dried at room temperature. Two kilograms of the air-dried peel of the plant was milled into fine powder. The powdered leaf was macerated in ethanol and extracted twice, on each occasion with 4 1itre of $70 \%$ ethanol at room temperature for $48 \mathrm{~h}$. The combined ethanol extract was concentrated in a rotary evaporator.

\section{Phytochemical Screening}

Chemical tests were carried out on orange and pomegranate peel ethanol extract for the qualitative determination of phytochemical constituents as per standard procedures [11].

1) Detection of alkaloids: Extracts were dissolved individually in dilute Hydrochloric acid and filtered. Filtrates were treated with Dragendroff's reagent (solution of Potassium Bismuth Iodide). The formation of a red precipitate indicates the presence of alkaloids.

2) Detection of flavonoids: Extracts were treated with few drops of sodium hydroxide solution. Formation of intense yellow colour, which becomes colourless on the addition of dilute acid, indicates the presence of flavonoids.

3) Detection of tannins: Gelatin Test: To the extract, $1 \%$ gelatin solution containing sodium chloride was added. The formation of a white precipitate indicates the presence of tannins.

4) Detection of saponins: $0.5 \mathrm{~g}$ of extract was shaken with $2 \mathrm{ml}$ of water. If foam produced persists for ten minutes it indicates the presence of saponins.

5) Detection of phytosterols: Libermann Burchard's test: Extracts were treated with chloroform and filtered. The filtrates were treated with few drops of acetic anhydride, boiled, and cooled. Conc. Sulphuric acid was added. The formation of a brown ring at the junction indicates the presence of phytosterols.
6) Detection of phenols: Extracts were treated with 3-4 drops of ferric chloride solution. The formation of bluishblack colour indicates the presence of phenols.

\section{Animal Experiment}

Twenty-four Wistar rats (Rattus norvegicus) weighing 150 $200 \mathrm{~g}$ were used in this study. The rats were obtained from the Laboratorium Biofarma Cisarua, Bandung. They were housed under standard laboratory conditions. The animals were given standard rat pellets (Rat Bio Indonesia) and tap water ad libitum.

\section{E. Induction of Experimental Diabetes}

Ethical approval is obtained from the research ethic commission team of Hasan Sadikin Hospital Bandung No.1276/UN6.KEP/EC/2018. The rats were randomly divided into four experimental groups, there are normal, diabetes, and two treatment groups that given a combination of $100 \mathrm{mg} / \mathrm{kg}$ orange and $50 \mathrm{mg} / \mathrm{kg}$ pomegranate peel extract (combination A), and a combination of $200 \mathrm{mg} / \mathrm{kg}$ orange and $100 \mathrm{mg} / \mathrm{kg}$ pomegranate peel extract (combination B). Each group consisted of six rats. Diabetes mellitus was induced by a single intraperitoneal injection of alloxan $(125 \mathrm{mg} / \mathrm{kg})$, freshly dissolved in $0.9 \%$ saline. Normal rats were injected with only $0.9 \%$ saline intraperitoneally. The animals'experiment became diabetic within 72 hours after alloxan administration. The diabetic state was confirmed by measuring basal blood glucose concentration 72 hours after alloxan injection. Diabetic was allowed to develop and stabilize in these alloxan-treated rats over a period of 3-5 days. All animals in all groups were kept and maintained under laboratory conditions and were allowed free access to food (standard pellet diet) and water ad libitum. Before the commencement of our experiments, both the normal and alloxan-treated diabetic test rats have fasted for $8 \mathrm{~h}$, but still allowed free access to water throughout. At the end of the $8 \mathrm{~h}$ fasting period, the blood glucose levels of the fasted normal and alloxan-treated rats were determined and recorded. Fasted alloxan-treated rats with blood glucose concentration $\geq 200$ $\mathrm{mg} / \mathrm{dl}$ were considered to be diabetic and used in this study. Blood sample was obtained from the tail vein of the animals and their fasting blood glucose level was determined in $\mathrm{mg} / \mathrm{dl}$ using a digital glucometer (Accu-chek®). The test compound [i.e., a combination of orange and pomegranate] was administered orally to the treated diabetic rats. The administration of extract combination was commenced from the $7^{\text {th }}$-day post alloxan injections for 12 days.

\section{F. Wound Creation}

The dorsal skin of each rat was shaved using an electric clipper. After 24 hours, all rats were anesthetized using ketamine (40 mg/kg; Sigma-Aldrich) and xylazine $(2 \mathrm{mg} / \mathrm{kg}$; Sigma-Aldrich) intraperitoneally and the shaved area was sterilized using $70 \%$ alcoholic solution. The wounds were made by cutting the dorsal skin with a diameter of $1.5 \mathrm{~cm}$ from the shaved area using toothed forceps and pointed scissors [6]. 
Percentage of wound reduction: To determine the percentage of wounds reduction, wounds were measured using vernier calliper and the changes in wounds size were calculated as the percentage of wound area that had healed. The reduction in the wound size was calculated according to the following formula:

$$
\text { Wound reduction }(\%) \quad=\frac{W o-W \mathrm{t}}{W o} \times 100
$$

Where, Wo is wound diameter on day zero, Wt is wound diameter on day $\mathrm{t}$.

\section{G. Statistical Analysis}

The data obtained were expressed as means $( \pm \mathrm{SD})$. The differences between the means were analyzed statistically with Anova. Values of $\mathrm{p}<0.05$ were taken to imply statistical significance and $p<0.01$ to imply statistical very significance.

\section{RESULTS}

\section{A. Results of Phytochemical Analysis}

The results of preliminary phytochemical analysis of orange and pomegranate peel ethanol extract were given in Table 1. The results revealed that alkaloids, flavonoids, tannins, polyphenols, and quinons were present in the sweet orange peel extract. Meanwhile, pomegranate peel extract contains flavonoids, tannins, polyphenols, and quinons.

TABLE I. PRELIMINARY PHYTOCHEMICAL ANALYSIS OF SWEET ORANGE AND POMEGRANATE PEEL ETHANOL EXTRACT

\begin{tabular}{|l|l|l|}
\hline \multicolumn{1}{|c|}{ Parameters } & \multicolumn{1}{|c|}{$\begin{array}{c}\text { Sweet orange peel } \\
\text { extract }\end{array}$} & $\begin{array}{c}\text { Pomegranate peel } \\
\text { extract }\end{array}$ \\
\hline Alkaloids & + & - \\
\hline Flavonoids & + & + \\
\hline Tannins & + & + \\
\hline Polyphenols & + & + \\
\hline Saponin & - & - \\
\hline Quinons & + & + \\
\hline
\end{tabular}

+ : present; - : not presen

\section{B. Effect of Combination of Sweet Orange and Pomegranate} on Blood Glucose Levels

Seventy-two hours after alloxan administration, the animals that had been treated with alloxan displayed hyperglycemia (blood glucose levels $\geq 200 \mathrm{mg} / \mathrm{dl}$ ). Meanwhile, animals that had not been treated with alloxan (normal group) did not show a significant increase in blood glucose levels. At the end of the study period (after 12 days of treatment), diabetic animals in the treated group presented decreasing in blood glucose levels very significantly $(\mathrm{p}<0.01)$. Final blood glucose levels in the group treated with combination B $(109.79 \pm 59.69 \mathrm{mg} / \mathrm{dl})$ was lower than combination A $(111.17 \pm 21.86 \mathrm{mg} / \mathrm{dl})$, however, this is not significantly different $(\mathrm{p}=0.999)$ (Table 2). The diabetes group without treatment did not show decreasing in blood glucose levels.
TABLE II CHANGES IN BLOOD GLUCOSE LEVELS IN NORMAL, DIABETES AND COMBINATION OF SWEET ORANGE AND POMEGRANATE TREATED DIABETIC RATS

\begin{tabular}{|c|c|c|c|}
\hline Groups & $\begin{array}{c}\text { Blood glucose } \\
\text { level } \\
\text { post aloksan } \\
\text { induction } \\
\text { Mean } \pm \\
\text { SD }(\mathrm{mg} / \mathrm{dL}) \\
\end{array}$ & $\begin{array}{c}\text { Blood glucose } \\
\text { level after } 12 \\
\text { days' treatment } \\
\text { Mean } \pm \\
\text { SD }(\mathrm{mg} / \mathrm{dL})\end{array}$ & $\mathbf{p}$ \\
\hline Normal & $85.00 \pm 9.38$ & $80.50 \pm 15.97$ & \\
\hline Diabetes & $203.33 \pm 54.93$ & $213.67 \pm 52.78$ & \\
\hline Combination A & $224.67 \pm 123.12$ & $111.17 \pm 21.86$ & $0.000 *$ \\
\hline Combination B & $374.54 \pm 96.15$ & $109.79 \pm 59.69$ & $0.000 *$ \\
\hline
\end{tabular}

\section{Effect of Combination of Sweet Orange and Pomegranate Peel Extract on Wound Healing}

A combination of sweet orange and pomegranate peel extract promotes the contraction of the wound in diabetic rats when compared to diabetic control (Fig. 1). The percentage of wound contraction on 12 days of observation showed that in diabetic control it was $24.33 \pm 8.04 \%$. In the treated groups it was found to be $68.83 \pm 5.23$ and $77.83 \pm 5.69$ at combination $\mathrm{A}$ and $\mathrm{B}$ respectively (Table 3 ).

TABLE III. EFFECT OF COMBINATION OF SWEET ORANGE AND POMEGRANATE PEEL ETHANOLIC EXTRACT ON EXCISION WOUND IN ALLOXAN INDUCED DIABETIC RATS

\begin{tabular}{|c|c|c|}
\hline Groups & $\begin{array}{c}\text { Percentage of wound } \\
\text { contraction at the end } \\
\text { of study }(\% \pm \mathrm{SD})\end{array}$ & $\mathbf{p}$ \\
\hline Normal & $56.67 \pm 8.16$ & \\
\hline Diabetes & $24.33 \pm 8.04$ & \\
\hline Combination $\mathrm{A}$ & $68.83 \pm 5.23$ & $0.000^{*}$ \\
\hline Combination B & $77.83 \pm 5.69$ & $0.000^{*}$ \\
\hline
\end{tabular}

Values are expressed as means $( \pm \mathrm{SD})$ of 6 rats ${ }^{*} \mathrm{p}<0.01$, compared to diabetes control

Combination A: combination of $100 \mathrm{mg} / \mathrm{kg}$ sweet orange and $50 \mathrm{mg} / \mathrm{kg}$ pomegranate

Combination B: combination of $200 \mathrm{mg} / \mathrm{kg}$ sweet orange and $100 \mathrm{mg} / \mathrm{kg}$ pomegranate

Observation showed that on the $12^{\text {th }}$ day onwards, the administration of a combination of sweet orange and pomegranate promoted the wound contraction faster than diabetic control. Wound contraction progressed much faster in combination $\mathrm{B}$ treated groups than the combination $\mathrm{A}$. The statistical analysis showed that extract combinations A and B caused a very significant contraction of the wound as compared to the diabetic wound control group $(p<0.01)$ at the end of the study period. There was no significant $(\mathrm{p}=0.120)$ increase in wound contraction observed between the administration of combination A and B. See figure 1 below. 


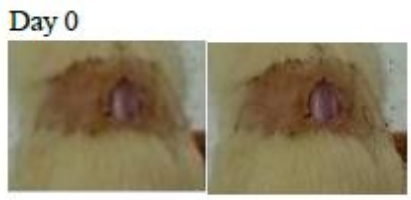

(A)

Day 12

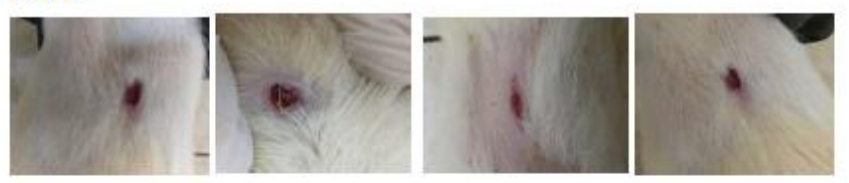

Fig. 1. Effect of combination of sweet orange and pomegranate on the wound contraction before treatment and at the end of the study showing wound healing after treatment. A: normal group, B: diabetes group, $\mathrm{C}$ : diabetes treatment with combination of $100 \mathrm{mg} / \mathrm{kg}$ sweet orange and $50 \mathrm{mg} / \mathrm{kg}$ pomegranate, D: diabetes treatment with $200 \mathrm{mg} / \mathrm{kg}$ sweet orange and $100 \mathrm{mg} / \mathrm{kg}$ pomegranate.

\section{DISCUSSION}

On phytochemical screening, the sweet orange extract showed the presence of alkaloids, flavonoids, tannins, polyphenols, and quinons. Several types of chemical compounds have been identified in fruits, peel, leaves, juice, and roots of sweet orange, which include the following groups: flavonoids, steroids, hydroxy amides, alkanes and fatty acids, coumarins, peptides, carbohydrates, carbamates and alkylamines, carotenoids, volatile compounds, and nutritional elements such as potassium, magnesium, calcium, and sodium [12]. A previous study showed that $C$. sinensis contains more total carotenoid and vitamin $\mathrm{C}$ compared to $C$. limon and $C$. paradise [6]. Meanwhile, pomegranate peel extract contains flavonoids, tannins, polyphenols, and quinons. Approximately $50 \%$ of the total pomegranate fruit weight corresponds to the peel, which is an important source of bioactive compounds such as phenolics, flavonoids, ellagitannins and proanthocyanidin compounds, minerals, potassium, nitrogen, calcium, phosphorus, magnesium, and complex polysaccharides [13]. Phenolic compounds are the main group of phytochemicals antioxidant, together with flavonoids, anthocyanins, and tannins, which are essential because of their biological and free radical scavenging activities [14].

The result revealed that a higher dosage of a combination of sweet orange and pomegranate peel extract (combination B) exhibited a greater reduction in blood levels [Table 2]. For example, the highest dosage of orange and pomegranate peel extract $(200 \mathrm{mg} / \mathrm{kg}$ sweet orange and $100 \mathrm{mg} / \mathrm{kg}$ pomegranate) showed a decrease of $264.33 \pm 71.49 \mathrm{mg} / \mathrm{dL}$ in blood glucose level when compared to the lowest dosage $(100 \mathrm{mg} / \mathrm{kg}$ sweet orange and $50 \mathrm{mg} / \mathrm{kg}$ pomegranate) that showed a decrease of $113.50 \pm 81.29 \mathrm{mg} / \mathrm{dL}$. The antidiabetic activity of sweet orange was also reported by Muhtadi et al. that showed the sweet orange peel extract doses of 125,250 , and $500 \mathrm{mg} / \mathrm{kg}$ could reduce blood glucose levels with decreasing values of $39.24 \%$ $\pm 4.96 \%, 46.18 \% \pm 6.60 \%$, and $61.36 \% \pm 5.57 \%$, respectively
[15]. Sweet orange anti-diabetic activity is caused by bioflavonoids such as hesperidine and naringin found in the peels of citrus fruit. Among C57BL / Ks J-db / db mice, these peels play an anti-diabetic role by regulating glucose control enzymes. They decrease glucose-6-phosphatase activity and pyruvate phosphoenolpyruvate. The antidiabetic ability of orange peel and juice appears to be mediated by antiperoxidation, inhibition of $\alpha$-amylase enzyme activity, which is responsible for transforming complex carbohydrates into glucose, increased hepatic glycogen content, stimulation of insulin secretion, and repair of pancreatic $\beta$-cell secretion defects [16].

A previous study showed that pomegranate juice and pomegranate seed treatment had no significant reduction in plasma glucose levels and no impact on plasma insulin compared to the diabetic control group [17]. Pomegranate leaves and fruit possesses significant antidiabetic, hypolipidemic, and antioxidant properties [18]. A previous study has been shown that both pomegranate seed and rind extracts have important anti-diabetic action, with rind extract having better activity than seed extract. The antidiabetic effect of these extracts can be due in part to their positive effect on the synthesis of glycogen in the liver, skeletal muscle, and cardiac muscle, and in part to their stimulatory action on insulin release [19].

Wound healing is a dynamic process consisting of four phases that are continuous, overlapping, and precisely programmed. Each phase's events should occur in a specific and controlled manner. Disruptions, aberrances, or prolongation of the cycle can result in delayed wound healing or chronic non-healing [1]. The wound healing activity in the ethanolic extract of the sweet orange and pomegranate combination as indicated in our present study involving excision wound models in diabetic conditions. The results supported the previous study that topical administration of $C$. sinensis methanol extract accelerates scar formation and promotes various stages of wound healing such as fibroplasia, collagen synthesis, wound contraction, and epithelization [20]. The ethanol extract of $C$. sinensis also significantly attributed to healing potential in diabetic conditions due to the antioxidant activity of vitamins and flavonoids [6].

Our study showed that the healing of skin wounds has been significantly delayed in diabetic rats, which may be correlated with the increased blood glucose levels of these animals. As expected, the diabetic conditions of the rats supported delaying the wound healing process by the abnormal physiological response. The impaired healing in diabetes patients involves multiple complex mechanisms of pathophysiology. In individuals with diabetes, more than 100 known physiological factors contribute to deficiencies in wound healing. These include reduced or impaired growth factor production, angiogenic response, macrophage function, accumulation of collagen, epidermal barrier function, tissue quantity, keratinocyte and fibroblasts migration and proliferation, number of epidermal nerves, and bone healing [2]. Hypoxia always accompanies DFUs, the same with venous stasis 
disease and pressure-related chronic non-healing wounds. A prolonged hypoxia situation that can be derived from insufficient perfusion, as well as insufficient angiogenesis, is detrimental to wound healing. Hyperglycemia may also increase oxidative stress when ROS production exceeds the antioxidant capacity. Neuropathy in diabetes is also likely to contribute to delayed wound healing [1].

\section{CONCLUSION}

The experiment results of the present study showed that a combination of sweet orange and pomegranate peel extract has hypoglycemic and wound healing effects. The extract contains some phytochemical compounds that may contribute to its activities. This study supported the traditional usage of this plant peel as antidiabetic.

\section{REFERENCES}

[1] S. Guo and L. a. DiPietro, "Critical review in oral biology \& medicine: Factors affecting wound healing," J. Dent. Res., vol. 89, no. 3, pp. 219 $229,2010$.

[2] H. Brem and M. Tomic-canic, "Cellular and molecular basis of wound healing in diabetes," J. Clin. Invest., vol. 117, no. 5, pp. 1219-1222, 2007.

[3] P. Milind and C. Dev, "Orange : Range of Benefits," Int. Res. J. Pharm., vol. 3, no. 7, pp. 3-7, 2012.

[4] N. Mallick and R.A. Khan, "Effect of Citrus sinensis ( Sweet Orange ) on coagulation," South Asian J. Exp. Biol., vol. 4, no. 2, pp. 54-60, 2014.

[5] S. Asgary and M. Keshvari, "Effects of citrus sinensis juice on blood pressure.," ARYA Atheroscler., vol. 9, no. 1, pp. 98-101, 2013.

[6] T.H.K.M Ahmad, M.N. Ansari, A. Alam, "Oral Dose of Citrus Peel Extracts Promotes Wound Repair in Diabetic Rats," Pakistan J. Biol. Sci., vol. 16, no. 20, pp. 1086-1094, 2013.

[7] S.K. Middha, T. Usha, and V. Pande, "A Review on Antihyperglycemic and Antihepatoprotective Activity of Eco-Friendly Punica granatum Pee Waste," Evidence-Based Complement. Altern. Med., pp. 1-10, 2013.

[8] M. Mohamed, A. El, N. Abdel, R. Salama, M.A.M. Saleh, and H.M Abo-taleb, "Evaluation of Antdiabetic , Hypocholesterolemic of Pomegranate ( Punica Granatum L .) Juice Powders and Peel Powder Extracts In Male Albino Rats,” J. Pharm. Biol. Sci., vol. 11, no. 6, pp. 53-64, 2016.
[9] S. Banihani, S. Swedan, and Z. Alquraan, "Pomegranate and type 2 diabetes," Nutr. Res., vol. 33, no. 5, pp. 341-8, 2013

[10] M. Almatar, R. Islam, O. Albarri, I. Var, and F. Köksal, "Pomegranate as a Possible Treatment in Reducing Risk of Developing Wound Pomegranate as a Possible Treatment in Reducing Risk of Developing Wound Healing, Obesity , Neurodegenerative Disorders , and Diabetes Mel- litus," Mini Rev. Med. Chem., vol. 18, pp. 1-19, 2017.

[11] H. Tiwari, P., Kumar, B., Kaur, M., Kaur, G., Kaur, "Phytochemical screening and Extraction: A Review," Int. Pharm. Sci., vol. 1, no. 1, pp. 98-106, 2011.

[12] J.M.J. Favela-Hernández, O. González-Santiago, M. a. Ramírez Cabrera, P. C. Esquivel-Ferriño, and M. D. R. Camacho-Corona, "Chemistry and pharmacology of Citrus sinensis," Molecules, vol. 21, no. 2, 2016.

[13] S. Sreekumar, H. Sithul, P. Muraleedharan, J.M. Azeez, and S. Sreeharshan, "Pomegranate Fruit as a Rich Source of Biologically Active Compounds," Biomed Res. Int., pp. 1-12, 2014.

[14] W. Elfalleh, N. Tilli, N. Nasri, Y. Yahiya, H. Hannachi, N. Chaira, M. Ying, and A. Ferchichi, "Antioxidant capacities of phenolic compounds and tocopherols from Tunisian pomegranate (Punica granatum) fruits,' J. Food Sci., vol. 76, no. 5, pp. 707-13, 2011.

[15] Muhtadi, Hartoyo, T. Azizah, A. Suhendi, and K. H. Yen, "Antidiabetic and antihypercholesterolemic activities of Citrus sinensis peel : in vivo study," Natl. J. Physiol. Pharmacol., vol. 5, no. 5, pp. 382-385, 2015.

[16] H. Parmar and A. Kar, "Medicinal Values of Fruit Peels from Citrus sinensis, Punica granatum, and Musa paradisiaca with Respect to Alterations in Tissue Lipid Peroxidation and Serum Concentration of Glucose, Insulin, and Thyroid Hormones," J. Med. Food, vol. 11, no. 2, pp. 376-381, 2008.

[17] M. Saeed, M. Naveed, J. Bibi, A.A. Kamboh, M.A. Arain, Q. A. Shah, M. Alagawany, M. E. A. El-hack, M. A. Abdel-latif, and M. I. Yatoo, "The promising pharmacological effects and therapeutic/medicinal applications of Punica granatum L. (pomegranate) as a functional food in human and animals," Recent Patents Inflamm. Allergy Drug Discov., vol. 12, no. 1, pp. 24-38, 2018.

[18] K.J. Salwe, D.O. Sachdev, Y. Bahurupi, and M. Kumarappan, "Evaluation of antidiabetic, hypolipedimic and antioxidant activity of hydroalcoholic extract of leaves and fruit peel of Punica granatum in male Wistar albino rats," J. Nat. Sci. Biol. Med., vol. 6, no. 1, pp. 56-62, 2015

[19] S. Das and G. Sarma, "Antidiabetic Action of Ethanolic Extracts of Punica granatum Linn . in Alloxan-induced," Stamford J. Pharm. Sci. vol. 2, no. 1, pp. 14-21, 2009.

[20] S.S. Ramasamy and A. Bhaskar, "Evaluation of the wound-healing potency of Citrus sinensis in Wistar albino rats," Der Pharm. Lett., vol. 8 , no. 1 ,pp. $161-168,2016$ 